\title{
Wind energy and sustainable electricity generation: evidence from Germany
}

\author{
Sakiru Adebola Solarin ${ }^{1}$ (D) Mufutau Opeyemi Bello ${ }^{2}$
}

Received: 17 September 2020 / Accepted: 6 September 2021 / Published online: 15 September 2021

(c) The Author(s), under exclusive licence to Springer Nature B.V. 2021

\begin{abstract}
Wind energy is one of the renewable energy sources that has been touted to address the challenges of energy security and environmental degradation. This is only attainable if countries with substantial wind energy potential use it in significant proportion to satisfy their energy needs. One promising sector where wind energy can be employed to actualize this potential is the electricity sector. However, the current reality is that fossil fuels still dominate the energy profiles of most economies of the world, including the advanced economies, with wind renewable energy source accounting for a very small proportion of the energy mix. Germany is one of the few countries that offers promising opportunities in deploying wind energy to its full potentials. This study therefore explores the feasibility of substituting wind energy for nuclear energy and other fossil fuels using Germany as a country of focus. We use the ridge regression procedure to analyse yearly time series data for the German power sector that spans the period 1986 to 2018. With respect to output elasticities of the energy inputs, the results reveal that wind and natural gas have positive output elasticity estimates while the estimates for nuclear and coal are negative. We also found that all the inputs pairs have positive substitution elasticity estimates between them. With respect to wind energy, the highest substitutability estimate occurred with nuclear power which is followed by natural gas and then coal. The study recommended that policies such as granting of tax credit for wind energy technology, reduction in property taxes for wind power facilities, and allocation of fund for research and development (R\&D) in wind energy technology are recommended to promote the use of wind energy in the economy.
\end{abstract}

Keywords Wind energy · Nuclear power · Dirty energy · Inter-fuel substitution · Electricity sector $\cdot$ Ridge regression $\cdot$ Germany

Sakiru Adebola Solarin

sakirusolarin@gmail.com

Mufutau Opeyemi Bello

muphtty_2004@yahoo.com

1 School of Economics, University of Nottingham Malaysia Jalan Broga, 43500 Semenyih, Malaysia

2 Faculty of Social Sciences, Department of Economics, University of Ilorin, PMB 1515, Ilorin,

Nigeria 


\section{Introduction}

The growing importance of renewable energy, especially among the developed countries, is expected to lead to reduction in fossil fuels in the energy mix which will eventually lead to decrease in greenhouse gas emissions. This is because fossil fuels usage generates emissions, while renewable energy sources are widely regarded as carbon neutral. One form of renewable energy that can be used to generate electricity is wind energy. Wind is a widely available source of energy. Wind energy is a green source of power because wind turbine does not directly generate emissions, thereby assisting nations to achieve their emission reduction goals and tackling climate change. It has been shown that wind energy consumption leads to a decrease in CO2 emissions (Kuskaya and Bilgili, 2020). The usage of wind energy reduces the need for water consumption in the process of electricity generation. Relative to nuclear power, wind energy is a less expensive source of energy.

Unlike nuclear energy, the usage of wind energy is not associated with major disasters. Wind power has lower maintenance and operational costs compared to nuclear power. Kyshtym disaster of 1957, Chernobyl disaster of 1986, Tokaimura nuclear accident of 1999 and Fukushima Daiichi nuclear disaster of 2011 are some of the major nuclear disasters that have been experienced over the years. These disasters have led to several deaths as well as clean-up costs running into several millions of dollars. Exposure to nuclear materials such as uranium can generate health risks. Wind energy consumption can promote economic growth as the promotion of renewable energy use can attract energy-related investment from both local and foreign investors. For instance, global offshore wind investment in the globe increased quadrupled in the first 6 months of 2020 (which amounts to \$35bn) despite being a coronavirus pandemic ravaged period (The Guardian, 2020).

As wind energy account for a small portion of the global electricity mix, the possibility of deriving all the benefits associated with wind energy is reliant on the degree at which it is feasible to change from other sources of energy (especially nuclear energy and fossil fuels) to wind energy in the electricity sector. For instance, in 2019, about 16.9 petawatt-hours or $63 \%$ of the aggregate electric power was produced from sources of fossil fuels, while 2.8 petawatt-hours or $10 \%$ of the aggregate electric power was produced from nuclear energy in the globe. Only 1.4 petawatt-hours or $5 \%$ of the aggregate electric power was produced from wind energy (British Petroleum, 2020).

However, it is difficult to find papers that have investigated the feasibility of replacing wind energy with fossil fuels or nuclear energy within the electricity sector. Many papers have concentrated on the inter-fuel substitution possibility between specific fossil fuels with specific renewable energy sources. Solarin and Bello (2019) have shown that it is possible to substitute coal, gas and oil with biomass in Brazil. Hossain and Serletis (2020) provided evidence for the feasibility of replacing biofuel for natural gas and biofuel for oil in the transportation industry of the USA. Tan and Lin (2020) provided evidence for substitution between coal and electricity, between electricity and oil, and between electricity and gas in China's energy intensive industries. There are even studies that have concentrated on the feasibility of substituting electricity generation from one source of nonrenewable energy with another source of nonrenewable energy. For instance, Mugabe et al. (2020) illustrated that it is possible to substitute coal with natural gas in the USA.

The empirical findings generated from these studies might not necessarily be applicable for electricity generation. Moreover, policy options for primary energy consumption or generation might be different to those available for electricity generation. Hence, few studies have also concentrated on inter-fuel substitution for electricity generation. Lin and Ankrah (2019a, 
b) illustrated that it is possible to shift from nonrenewable power generation system to renewable power generation system in Ghana and Nigeria, respectively. Kim (2019) disclosed that it is not possible to substitute nuclear power with renewable energy sources in Korea. Bello et al. (2020) suggested that it is possible to substitute coal and gas with hydroelectricity in the course of generating electric power in a south-east Asian country, Malaysia.

We aim to contribute to the existing body of work by investigating the feasibility of replacing the fossil fuels - natural gas and coal, as well as nuclear energy for wind power in the process of producing electric power in Germany. We have chosen Germany because of the following reasons. Firstly, Germany is not only among the biggest economies in the world, but also has the largest economy in Europe (World Bank, 2020). Secondly, being responsible for $16 \%$ of the aggregate energy consumption in 2019 , the country has the biggest energy sector in the continent (British Petroleum, 2020). Thirdly, by producing carbon dioxide of 0.7 billion tonnes in 2019, the nation has the largest carbon dioxide in Europe and accounts for $17 \%$ of the aggregate carbon dioxide produced in the continent (British Petroleum, 2020). Fourthly, similar to the scenario in numerous economies, fossil fuels account for the bulk of electric power in Germany. About 0.3 petawatt-hours or $44 \%$ of the aggregate electric power was produced from fossil fuels sources. The total electricity generated through the renewable energy sources was 244 terawatt-hours, which is under $40 \%$ of the total. Only 0.1 petawatthours or $21 \%$ of the aggregate electricity was produced from wind energy (British Petroleum, 2020). Hence, this has made the power sector to be a key source of the country's emissions. Production of heat and electricity led to CO2 emissions of 303 million tonnes or $42 \%$ of the aggregate fuel combustion induced CO2 emissions in Germany in 2017 (International Energy Association, 2020).

Fifthly, the government in Germany has introduced several policies and initiatives aimed at improving the popularity of wind energy. Some of these initiatives and policies include Offshore Grid Development Plan of 2005, Electricity Grid Development Plan of 2005, Energy Act passed in 2011 and Renewable Energy Act of 2017. Sixthly, the use of nuclear power to generate electricity has decreased substantially over the years. For instance, nuclear energy accounted for 133 terawatt-hours of electricity generated or $28 \%$ of the total electricity generated in 2010 . However, by 2015 , nuclear energy accounted for 86.8 terawatt-hours of electricity generated or $16 \%$ of the total electricity generated (which still made Germany, the seventh-biggest generator of nuclear energy in the globe). The German government approved the amendment of the Nuclear Energy Act of 2002, designed at decreasing reliance on nuclear energy in the country (World Wind Energy Association, 2018). Aftermath of the Fukushima disaster in Japan in March 2011, the authorities in Germany choose to shut down eight reactors that were in existent before 1980 due to public complaints and to shut down the remaining nine nuclear reactors in Germany before 2022 (Energy Information Administration, 2016).

The remaining parts of the paper are arranged in the following form. Section 2 describes the methodology, as well as the datasets that have been employed in this study. Section 3 presents the empirical findings and discussion resulting from the findings, while Sect. 4 contains the conclusion and policy implications of the paper.

\section{Methodology}

\subsection{Model}

We begin by specifying the following production function: 


$$
Y=f(K, L, E)
$$

where output $(Y)$ depends on Energy $(E)$, Labour $(L)$ and physical capital stock $(K)$. Energy (E) is supposed to be homothetic and weakly separable in its various components. For Germany, the main energy types that we have considered in this research are Coal $(C)$, Gas $(G)$, Wind $(W)$ and Nuclear energy $(N)$. Thus, segregating energy into its sub-components, Eq. (1) is re-written as:

$$
Y=f(K, L, E(C, G, W, N))
$$

We then transform Eq. (2) into a double differentiable transcendental logarithmic or trans$\log$ production specification as follows:

$$
\ln Y_{t}=\alpha_{0}+\sum_{i} \alpha_{i} \ln X_{i t}+\frac{1}{2} \sum_{i} \sum_{j} \alpha_{i j} \ln X_{i t} \ln X_{j t}
$$

Equation (1) is the general form of a second-order Taylor Series representation where $Y$ is the output and the $X_{s}$ is the various units of input combinations (i.e. $K, L, C, G, W$, and $N$ ) with subscripts $i$ and $j$ representing such combinations. Subscript $t$ denotes period, the $\alpha_{s}$ is the parameter estimates while ln shows that the variables are in their natural logarithm forms.

To avoid overparameterization, we have reduced the number of estimable parameters by including just the trans-log components of the energy elements as these are the focus of this study. Thus, the specific trans-log production function is stated as follows:

$$
\begin{aligned}
\ln Y_{t}= & \alpha_{0}+\alpha_{K} \ln K_{t}+\alpha_{L} \ln L_{t}+\alpha_{C} \ln C_{t}+\alpha_{G} \ln G_{t}+\alpha_{W} \ln W_{t}+\alpha_{N} \ln N_{t}+\alpha_{C G} \ln C_{t} \ln G_{t} \\
& +\alpha_{C W} \ln C_{t} \ln W_{t}+\alpha_{C N} \ln C_{t} \ln N_{t}+\alpha_{G W} \ln G_{t} \ln W_{t}+\alpha_{G N} \ln G_{t} \ln N_{t}+\alpha_{W N} \ln W_{t} \ln N_{t} \\
& +\alpha_{C C}\left(\ln C_{t}\right)^{2}+\alpha_{G G}\left(\ln G_{t}\right)^{2}+\alpha_{W W}\left(\ln W_{t}\right)^{2}+\alpha_{N N}\left(\ln N_{t}\right)^{2}
\end{aligned}
$$

The parameter estimates of specification in (4) are used to derive the estimates of the output of elasticities of each of the energy sources. The output elasticity estimates are subsequently employed to produce the estimates of substitution coefficients between the energy inputs.

The output elasticity of an input $i$ is computed as:

$$
\eta_{i t}=\frac{\partial \ln Y_{t}}{\partial \ln X_{i t}}=\alpha_{i}+\sum_{j} \alpha_{i j} \ln X_{j t}
$$

Thus, for the respective energy inputs $(C),(G),(W)$ and $(N)$, the output elasticity is obtained as:

$$
\begin{aligned}
& \text { Coal : } \eta_{C t}=\frac{\partial \ln Y_{t}}{\partial \ln C_{c t}}=\alpha_{C}+\alpha_{C G} \ln G_{t}+\alpha_{C W} \ln W_{t}+\alpha_{C N} \ln N_{t}+2 \alpha_{C C} \ln C_{t} \\
& \text { Gas : } \eta_{G t}=\frac{\partial \ln Y_{t}}{\partial \ln G_{g t}}=\alpha_{G}+\alpha_{C G} \ln C_{t}+\alpha_{G W} \ln W_{t}+\alpha_{G N} \ln N_{t}+2 \alpha_{G G} \ln G_{t}
\end{aligned}
$$

Wind Energy : $\eta_{W t}=\frac{\partial \ln Y_{t}}{\partial \ln W_{w t}}=\alpha_{W}+\alpha_{C W} \ln C_{t}+\alpha_{G W} \ln G_{t}+\alpha_{W N} \ln N_{t}+2 \alpha_{W W} \ln W_{t}$ 


$$
\text { Nuclear Energy : } \eta_{N t}=\frac{\partial \ln Y_{t}}{\partial \ln N_{n t}}=\alpha_{N}+\alpha_{C N} \ln C_{t}+\alpha_{G N} \ln G_{t}+\alpha_{W N} \ln W_{t}+2 \alpha_{N N} \ln N_{t}
$$

where $\eta_{C t}, \eta_{G t}, \eta_{W t}$, and $\eta_{N t}$ specify elasticities of Coal, Gas, Wind, and Nuclear energy outputs, respectively. Given the estimates of the output elasticities of the energy inputs, the estimates of the substitution elasticities between the energy inputs are given as follows:

$$
\sigma_{i j}=\left[1+2\left[\alpha_{i j}-\alpha_{i i}\left(\eta_{j} / \eta_{i}\right)-\alpha_{j j}\left(\eta_{i} / \eta_{j}\right)\right] \cdot\left[\eta_{i}+\eta_{j}\right]^{-1}\right]^{-1} \quad(i \neq j ;=c, g, w, n)
$$

The elasticity estimates are symmetry, i.e. $\left(\sigma_{i j}=\sigma_{j i}\right)$. The substitution elasticity between the respective energy pairs is therefore calculated as:

Coal and Gas : $\sigma_{C G}=\left[1+2\left[\alpha_{C G}-\alpha_{C C}\left(\eta_{G} / \eta_{C}\right)-\alpha_{G G}\left(\eta_{C} / \eta_{G}\right)\right] \cdot\left[\eta_{C}+\eta_{G}\right]^{-1}\right]^{-1}$

Coal and Wind : $\sigma_{C W}=\left[1+2\left[\alpha_{C W}-\alpha_{C C}\left(\eta_{W} / \eta_{C}\right)-\alpha_{W W}\left(\eta_{C} / \eta_{W}\right)\right] \cdot\left[\eta_{C}+\eta_{W}\right]^{-1}\right]^{-1}$

Coal and Nuclear : $\sigma_{C N}=\left[1+2\left[\alpha_{C N}-\alpha_{C C}\left(\eta_{N} / \eta_{C}\right)-\alpha_{N N}\left(\eta_{C} / \eta_{N}\right)\right] \cdot\left[\eta_{C}+\eta_{N}\right]^{-1}\right]^{-1}$

Gas and Wind : $\sigma_{G W}=\left[1+2\left[\alpha_{G W}-\alpha_{G G}\left(\eta_{W} / \eta_{G}\right)-\alpha_{W W}\left(\eta_{G} / \eta_{W}\right)\right] \cdot\left[\eta_{G}+\eta_{W}\right]^{-1}\right]^{-1}$

Gas and Nuclear : $\sigma_{G N}=\left[1+2\left[\alpha_{G N}-\alpha_{G G}\left(\eta_{N} / \eta_{G}\right)-\alpha_{N N}\left(\eta_{G} / \eta_{N}\right)\right] \cdot\left[\eta_{G}+\eta_{N}\right]^{-1}\right]^{-1}$

Wind and Nuclear : $\sigma_{W N}=\left[1+2\left[\alpha_{W N}-\alpha_{W W}\left(\eta_{N} / \eta_{W}\right)-\alpha_{N N}\left(\eta_{W} / \eta_{N}\right)\right] \cdot\left[\eta_{W}+\eta_{N}\right]^{-1}\right]^{-1}$

In Eqs. (11-16), positive estimate values imply that the energy pairs are substitutes while negative values connote complementary relationships between the energy pairs.

\section{Data}

The dataset entails annual time series data on production, stock of physical capital, labour, coal, gas, wind energy and nuclear energy for Germany spanning the period 1986 to 2018. We have not included oil in the analysis as the country generates a negligible amount of electricity from it. Real GDP is used as proxy for output, while data for physical capital stock are represented by the Gross Fixed Capital Formation (GFCF). To address inflationary trend, data on both the real GDP and the GFCF have been obtained at constant 2010US\$ from the world development indicators of the World Bank (2020). Labour, obtained from the data and analysis section of the Conference Board (2020), is computed as persons employed (in thousands per persons). Data on the energy series, in million tonnes of oil equivalent (MTOE), were sourced from the Statistical Review of World Energy, which is being printed by British Petroleum (BP) (2020). 


\section{Ridge regression procedure}

Extreme multicollinearity can cause serious problem in model estimation. This is especially the case when the model includes squared exponential explanatory terms like the trans-log model in Eq. (4). A severe case of multicollinearity usually exaggerates the standard errors of the parameter estimates and reduces the t-statistics. This does not only lead to insignificant probability values and grossly inaccurate parameter estimates but also ultimately results into loss of overall projecting ability of the model. In such case, the use of the conventional ordinary least square procedure becomes not only inconsistent but also misleading. To ascertain the propriety or otherwise of the OLS procedure, we commence the estimation procedure by first conducting a test for multicollinearity through the examination of the variance inflation factors of the regressors and the condition number of the Eigenvalues of correlation of the variables. The outcomes of the multicollinearity test, displayed in Table 1, shows that not only is the variance inflation factors for each of the regressors significantly exceed 10 but also the condition number of the Eigenvalues of correlation of some series exceeds 100 thereby establishing the existence of an extreme multicollinearity problem and rendering the application of the OLS technique unsuitable in this circumstance.

To circumvent these challenges, Hoerl (1962) developed a unique regression procedure called the ridge regression procedure. The ridge regression approach involves the modification of the OLS parameter estimate by introducing a penalty parameter knows as a biasing constant $(c)$. Therefore, the original matrix for the OLS coefficient estimate $\boldsymbol{\alpha}_{\text {ols }}=\left(\mathbf{x}^{\prime} \mathbf{x}\right)^{-1} \mathbf{x}^{\prime} \mathbf{y}$ is modified into a ridge expression as $\boldsymbol{\alpha}_{\text {ridge }}=\left(\mathbf{x}^{\prime} \mathbf{x}+c \mathbf{I}\right)^{-1} \mathbf{x}^{\prime} \mathbf{y}$ where $c$ is

Table 1 Least squares multicollinearity test result

\begin{tabular}{llll}
\hline Independent variable & $\begin{array}{l}\text { Variance } \\
\text { inflation } \\
\text { factors }\end{array}$ & Eigenvalues & Condition number \\
\hline InK & 25.0023 & 10.7306 & 1.00000 \\
InL & 28.1082 & 3.460019 & 3.10000 \\
InC & $203,922.7$ & 1.088957 & 9.85000 \\
InG & $729,133.1$ & 0.468429 & 22.9100 \\
InW & $1,014,980$ & 0.11589 & 92.5900 \\
InN & $114,518.5$ & 0.085683 & 125.240 \\
InC ${ }^{*}$ InG & $591,200.9$ & 0.049124 & 218.440 \\
InC*InW & $1,052,053$ & 0.000667 & $16,082.73$ \\
InC ${ }^{*}$ InN & $203,274.8$ & 0.000493 & $21,766.77$ \\
InG*InW & $44,959.23$ & 0.000064 & $168,348.6$ \\
InG*InN & $13,216.56$ & 0.000036 & $302,184.1$ \\
InW*InN & $22,378.5$ & 0.000023 & $461,031.1$ \\
InC*InC & $251,670.7$ & 0.000010 & $1,103,073$ \\
InG*InG & $41,096.09$ & 0.000002 & $4,538,996$ \\
InW*InW & 82.5726 & 0.000001 & $7,274,368$ \\
InN*InN & $26,460.14$ & 0.000000 & $32,351,833$ \\
\hline
\end{tabular}

Multicollinearity is severe as the variance inflation factors exceeds 10 and some condition figures of the Eigenvalues of correlations of some series exceed 100 
the penalty term whose values ranges from 0 to 1 and $\mathbf{I}$ is an identity matrix. The penalty parameter that is equal to zero corresponds to the OLS estimates.

Hoerl and Kennard (1970) suggested the usage of the ridge trace as a methodical means of finding the optimum value of $c$. The ridge trace plots the ridge regression coefficients as a function of $c$, and the value of $c$, for which the regression coefficients stabilise, is selected as the optimum. A ridge parameter of 0.184 has been selected as the optimum value of $c$ based on the ridge trace plot shown in Fig. 1 as the parameter estimates seem to stabilise around this value.

Furthermore, Table 2 is also used to show the effect of the ridge regression method on the variance inflation factors. As can be seen, changing the penalty parameters decreases the variance inflation factors. The zero value of the penalty parameter corresponds to the variance inflation factors for the OLS estimates which are very large, but steady increase in the penalty parameter continues to decrease the variance inflation factors until the value of 0.184 where the variance inflation factors for all variables have come under 10 and multicollinearity successfully addressed.

\section{Results and discussion}

We begin the discussion of the results by presenting the results of the parameter estimates of the ridge regression procedure in Table 3. The table shows the figures of the variance inflation factor for each of the parameter, and as can be observed, these figures are less than 10 , in so doing, supporting the fact that the issue of multicollinearity has been successfully resolved. In addition to this, the $f$-ratio is $1 \%$ significant with a $97.1 \% R$-square signifying a robust goodness of fit and explanatory power of the parameters in the regression.

Fig. 1 Ridge trace plot

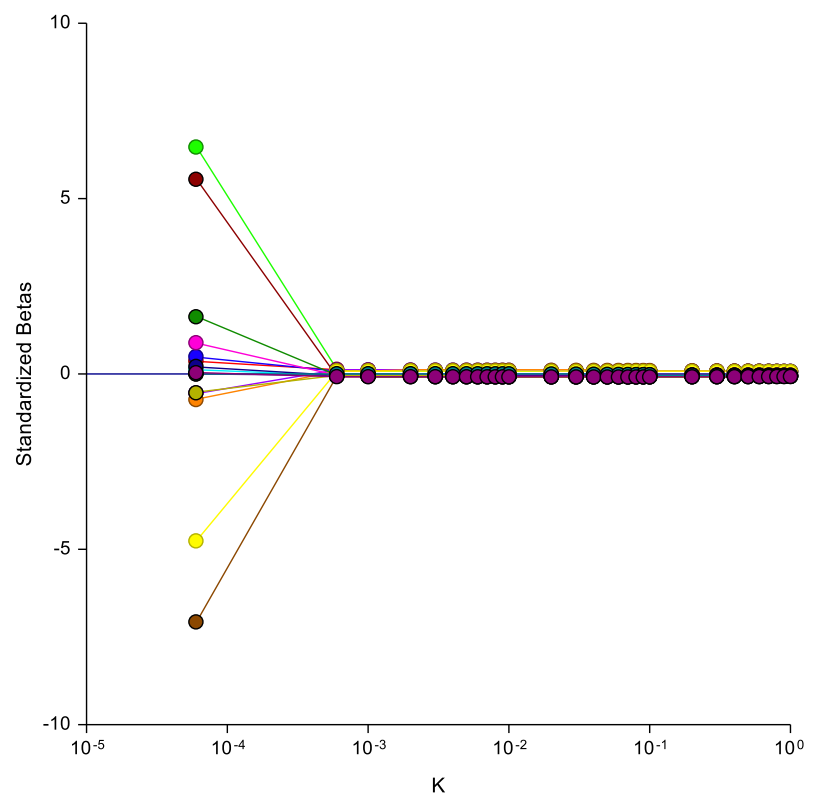




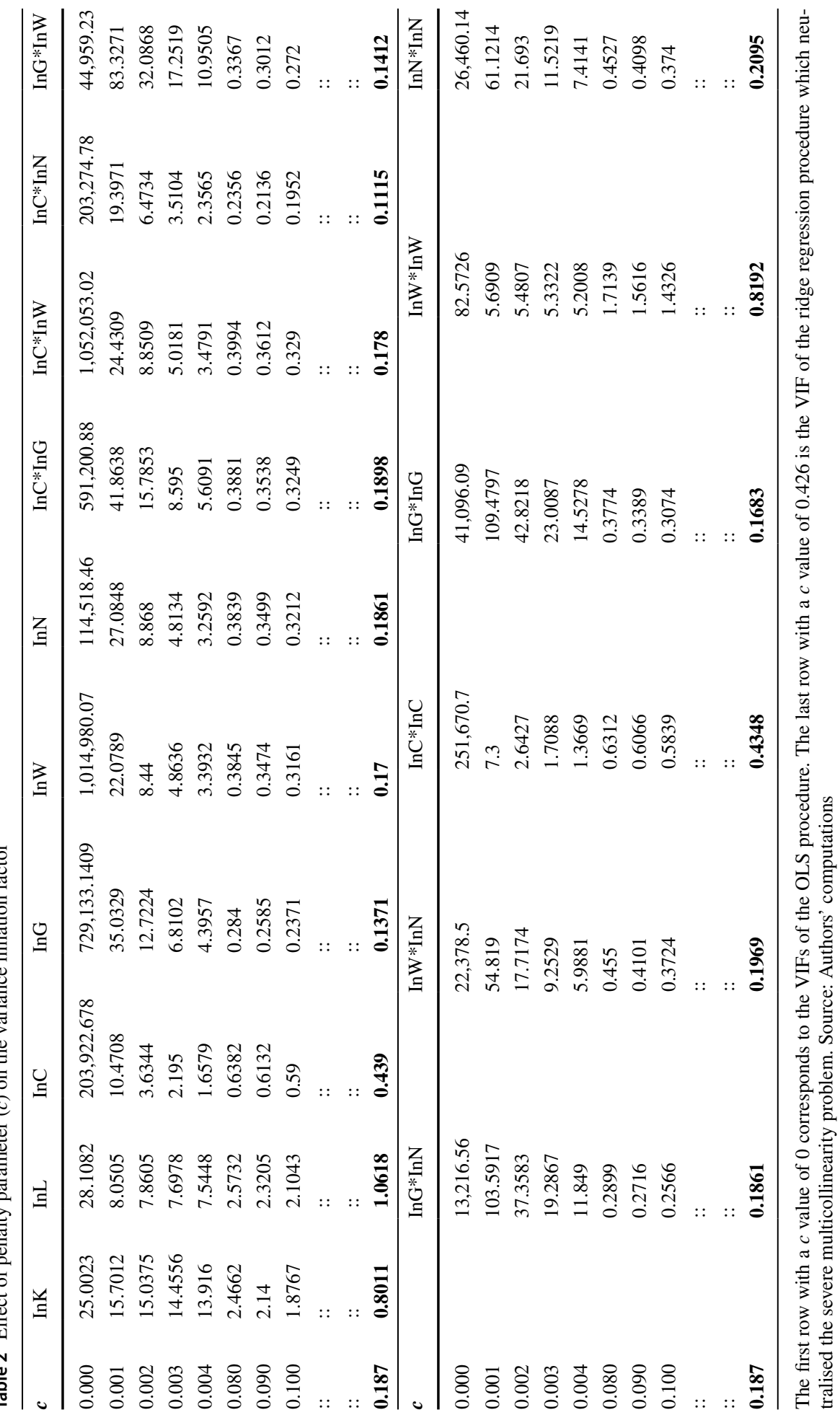


From the parameter estimates of the ridge regression depicted in Table 3, the output elasticities of each of the energy inputs are obtained using Eqs. (6), (7), (8) and (9), respectively, for coal, gas, wind, and nuclear energy and the empirical findings are depicted in Table 4. The result shows that the average output elasticities for both gas and wind energy are positive, while the corresponding figures for both coal and nuclear are negative. This outcome is not totally surprising as wind energy is considered a cleaner energy with an increasing share in the energy profile of Germany over the recent years. Similarly, gas is considered less harmful compared to other fossil fuel like coal which is perhaps most environmentally detrimental to the environment after oil, while nuclear, on the other hand, has been experiencing a downward trend in the energy profile of Germany. The estimates of the output elasticities are employed to compute the elasticities of substitution estimates between the energy pairs. These are given in Table 5 with positive estimate values between all energy inputs averaging unity. This implies that all energy pairs considered in this study for Germany are substitutes. With specific reference to wind, the highest substitutability estimate is nuclear energy, followed by gas and then coal.

The foregoing results suggest that wind energy has positive impact on economic growth, as well as being able to substitute nuclear energy, coal and natural gas in Germany. The results can be attributed to several reasons. First, wind power is cost-effective in many regions. Wind deployment is associated with integrated costs including balancing costs (arising from uncertainty that is connected to the adoption of wind power); grid costs

Table 3 Ridge regression parameter estimates Source: Authors' computations

\begin{tabular}{|c|c|c|c|}
\hline Independent variable & Parameter estimates & $t$-stat & $\begin{array}{l}\text { Variance } \\
\text { inflation } \\
\text { factor }\end{array}$ \\
\hline Constant & 18.604 & & \\
\hline InK & $0.193^{\mathrm{A}}$ & 4.479 & 0.801 \\
\hline InL & $0.290^{\mathrm{C}}$ & 1.858 & 1.062 \\
\hline $\mathrm{InC}$ & -0.008 & -0.130 & 0.439 \\
\hline InG & $0.020^{\mathrm{A}}$ & 2.957 & 0.137 \\
\hline InW & $0.006^{\mathrm{A}}$ & 7.373 & 0.170 \\
\hline $\mathrm{InN}$ & $-0.036^{\mathrm{A}}$ & -3.181 & 0.186 \\
\hline $\operatorname{InC} * \operatorname{InG}$ & $0.005^{\mathrm{A}}$ & 2.880 & 0.189 \\
\hline $\operatorname{InC} * \operatorname{InW}$ & $0.001^{\mathrm{A}}$ & 7.283 & 0.178 \\
\hline $\operatorname{InC} C^{*} \operatorname{InN}$ & $-0.005^{\mathrm{A}}$ & -3.493 & 0.111 \\
\hline $\operatorname{InG}{ }^{*} \operatorname{InW}$ & $0.002^{\mathrm{A}}$ & 7.796 & 0.141 \\
\hline $\operatorname{InG} \mathrm{InN}^{*}$ & 0.002 & 0.844 & 0.186 \\
\hline $\operatorname{InW} * \operatorname{InN}$ & $0.001^{\mathrm{A}}$ & 6.868 & 0.197 \\
\hline $\operatorname{InC} C^{*} \operatorname{InC}$ & -0.001 & -0.161 & 0.435 \\
\hline $\operatorname{InG} \mathrm{InG}^{*}$ & $0.002^{\mathrm{A}}$ & 2.436 & 0.168 \\
\hline InW*InW & -0.003 & -0.464 & 0.819 \\
\hline $\operatorname{InN} * \operatorname{InN}$ & $-0.004^{\mathrm{A}}$ & -2.883 & 0.209 \\
\hline \multicolumn{4}{|l|}{ R Squared: 0.971} \\
\hline F-ratio: $33.0621(0.000)$ & & & \\
\hline
\end{tabular}

A implies $1 \%$ level of significance, $\mathrm{C}$ implies $10 \%$ level of significance, Figures in parenthesis are probability values. 
Table 4 Output elasticity estimates Source: Authors' computations

\begin{tabular}{|c|c|c|c|c|}
\hline Year & $\eta_{\varepsilon} \mathrm{C}$ & $\eta_{E} \mathrm{G}$ & $\eta_{\varepsilon} \mathrm{W}$ & $\eta_{\varepsilon} \mathrm{N}$ \\
\hline 1986 & -0.031 & 0.058 & 0.027 & -0.100 \\
\hline 1987 & -0.031 & 0.060 & 0.027 & -0.100 \\
\hline 1988 & -0.029 & 0.062 & 0.026 & -0.099 \\
\hline 1989 & -0.028 & 0.065 & 0.026 & -0.097 \\
\hline 1990 & -0.027 & 0.066 & 0.025 & -0.096 \\
\hline 1991 & -0.026 & 0.066 & 0.025 & -0.095 \\
\hline 1992 & -0.026 & 0.067 & 0.025 & -0.094 \\
\hline 1993 & -0.025 & 0.068 & 0.024 & -0.093 \\
\hline 1994 & -0.024 & 0.069 & 0.024 & -0.092 \\
\hline 1995 & -0.023 & 0.071 & 0.024 & -0.091 \\
\hline 1996 & -0.022 & 0.072 & 0.024 & -0.091 \\
\hline 1997 & -0.022 & 0.073 & 0.024 & -0.091 \\
\hline 1998 & -0.021 & 0.073 & 0.024 & -0.090 \\
\hline 1999 & -0.021 & 0.074 & 0.024 & -0.090 \\
\hline 2000 & -0.020 & 0.075 & 0.023 & -0.089 \\
\hline 2001 & -0.020 & 0.075 & 0.024 & -0.089 \\
\hline 2002 & -0.019 & 0.076 & 0.023 & -0.088 \\
\hline 2003 & -0.018 & 0.077 & 0.023 & -0.088 \\
\hline 2004 & -0.018 & 0.077 & 0.023 & -0.088 \\
\hline 2005 & -0.017 & 0.078 & 0.023 & -0.087 \\
\hline 2006 & -0.017 & 0.078 & 0.023 & -0.087 \\
\hline 2007 & -0.016 & 0.079 & 0.023 & -0.086 \\
\hline 2008 & -0.015 & 0.079 & 0.023 & -0.086 \\
\hline 2009 & -0.015 & 0.078 & 0.023 & -0.085 \\
\hline 2010 & -0.015 & 0.079 & 0.023 & -0.085 \\
\hline 2011 & -0.014 & 0.078 & 0.023 & -0.083 \\
\hline 2012 & -0.014 & 0.078 & 0.023 & -0.083 \\
\hline 2013 & -0.014 & 0.078 & 0.022 & -0.083 \\
\hline 2014 & -0.015 & 0.077 & 0.022 & -0.083 \\
\hline 2015 & -0.014 & 0.078 & 0.022 & -0.082 \\
\hline 2016 & -0.012 & 0.078 & 0.022 & -0.081 \\
\hline 2017 & -0.011 & 0.079 & 0.022 & -0.079 \\
\hline 2018 & -0.011 & 0.078 & 0.022 & -0.079 \\
\hline Average & -0.020 & 0.073 & 0.024 & -0.089 \\
\hline
\end{tabular}

(which are associated with the adaptation of the grid to wind energy generation), and profile costs (which are associated with the need for backup capacity, particularly during peakload periods). The integrated costs are collectively less than the costs that would have been incurred if most of the alternative sources of electricity were being utilised. Its appeal has risen over the years because of its substantial cost reduction and its non-susceptibility to oil price volatility (Ortega-Izquierdo \& del Río, 2020).

Another rationale for the above the results is the smaller space required by wind technology and the flexibility in its use. Wind energy stations usually require less space than conventional power stations. Therefore, the freed space and land resulting from the shift 
Table 5 Substitution elasticity estimates Source: Authors' computations

\begin{tabular}{lllllll}
\hline Year & $\sigma_{\mathrm{CG}}$ & $\sigma_{\mathrm{CW}}$ & $\sigma_{\mathrm{CN}}$ & $\sigma_{\mathrm{GW}}$ & \multicolumn{1}{l}{$\sigma_{\mathrm{GN}}$} & $\sigma_{\mathrm{WN}}$ \\
\hline 1986 & 0.7623 & 0.9548 & 0.8101 & 0.9773 & 1.1906 & 0.9822 \\
1987 & 0.7836 & 0.9554 & 0.8093 & 0.9766 & 1.1890 & 0.9821 \\
1988 & 0.8095 & 0.9559 & 0.8080 & 0.9750 & 1.1874 & 0.9820 \\
1989 & 0.8393 & 0.9566 & 0.8056 & 0.9739 & 1.1867 & 0.9817 \\
1990 & 0.8526 & 0.9565 & 0.8032 & 0.9726 & 1.1885 & 0.9815 \\
1991 & 0.8592 & 0.9565 & 0.8020 & 0.9721 & 1.1894 & 0.9814 \\
1992 & 0.8667 & 0.9564 & 0.8009 & 0.9710 & 1.1902 & 0.9813 \\
1993 & 0.8780 & 0.9564 & 0.7989 & 0.9701 & 1.1922 & 0.9811 \\
1994 & 0.8886 & 0.9566 & 0.7974 & 0.9698 & 1.1937 & 0.9809 \\
1995 & 0.9007 & 0.9570 & 0.7960 & 0.9696 & 1.1954 & 0.9807 \\
1996 & 0.9080 & 0.9574 & 0.7958 & 0.9696 & 1.1958 & 0.9807 \\
1997 & 0.9136 & 0.9576 & 0.7951 & 0.9693 & 1.1972 & 0.9806 \\
1998 & 0.9224 & 0.9577 & 0.7935 & 0.9690 & 1.2006 & 0.9804 \\
1999 & 0.9244 & 0.9577 & 0.7933 & 0.9689 & 1.2013 & 0.9804 \\
2000 & 0.9286 & 0.9576 & 0.7927 & 0.9683 & 1.2039 & 0.9803 \\
2001 & 0.9349 & 0.9580 & 0.7921 & 0.9685 & 1.2060 & 0.9802 \\
2002 & 0.9414 & 0.9579 & 0.7906 & 0.9681 & 1.2113 & 0.9801 \\
2003 & 0.9483 & 0.9583 & 0.7901 & 0.9682 & 1.2153 & 0.9800 \\
2004 & 0.9518 & 0.9582 & 0.7894 & 0.9679 & 1.2194 & 0.9799 \\
2005 & 0.9602 & 0.9585 & 0.7880 & 0.9680 & 1.2270 & 0.9797 \\
2006 & 0.9624 & 0.9586 & 0.7880 & 0.9681 & 1.2294 & 0.9797 \\
2007 & 0.9736 & 0.9585 & 0.7849 & 0.9676 & 1.2501 & 0.9793 \\
2008 & 0.9790 & 0.9587 & 0.7844 & 0.9679 & 1.2574 & 0.9791 \\
2009 & 0.9777 & 0.9582 & 0.7828 & 0.9674 & 1.2576 & 0.9790 \\
2010 & 0.9810 & 0.9586 & 0.7832 & 0.9677 & 1.2618 & 0.9790 \\
2011 & 0.9947 & 0.9580 & 0.7787 & 0.9669 & 1.3143 & 0.9784 \\
2012 & 0.9915 & 0.9577 & 0.7785 & 0.9666 & 1.3094 & 0.9784 \\
2013 & 0.9851 & 0.9575 & 0.7791 & 0.9663 & 1.2924 & 0.9786 \\
2014 & 0.9814 & 0.9571 & 0.7788 & 0.9659 & 1.2858 & 0.9786 \\
2015 & 0.9897 & 0.9570 & 0.7770 & 0.9655 & 1.3276 & 0.9784 \\
2016 & 1.0120 & 0.9575 & 0.7739 & 0.9659 & 1.5351 & 0.9778 \\
2017 & 1.0307 & 0.9573 & 0.7703 & 0.9655 & -1.7761 & 0.9773 \\
2018 & 1.0294 & 0.9570 & 0.7698 & 0.9652 & -4.9650 & 0.9773 \\
Average & 0.9260 & 0.9574 & 0.7910 & 0.9692 & 1.1414 & 0.9800 \\
\hline & & & & & &
\end{tabular}

to wind energy can be employed for other productive projects. Wind turbines can be mounted in locations that are remote in nature. Besides, wind farms capacity is changeable in line with the energy and electricity needs. It is possible to build wind turbines on existing ranches or farms. This significantly aids the productive activities in rural areas. It is possible for ranchers and farmers to continue to work on their land because the wind turbines occupy only a portion of the land. For their use of the leased land, the owners of wind power plant regularly pay rents to the ranchers or farmers, offering landowners with extra income. 
The foregoing results can also be justified on the basis that increase in investment has accompanied the deployment of wind energy in Germany. The deployment of wind energy technologies requires both public and private investments. In Germany, public investment on wind energy technologies has increased over the years. For instance, the government support for technology increased nine-fold from 740 million euro in 2009 to 6520 million euro in 2016 (Ortega-Izquierdo \& del Río, 2020). Investment in new technology increases productivity and the productive capacity of the economy, which assists to shift the longrun aggregate supply to the right. An increase in long-run aggregate supply is essential for long-term economic growth. Investment leads to a substantial rise in productivity, as well as an increase in the productive capacity of the country.

Another justification for the foregoing empirical findings is that wind is a domestic source of energy. Hence, substituting fossil fuels with wind energy is likely to reduce the dependence of the country on imported fuels, which grain the resources. The saved resources, as a result of the deployment of wind energy, can be used to fund other productive activities such as research and development. Germany is regarded as the biggest importer of natural gas in the globe. The largest gas imports come from the Netherlands, Norway and Russia via the Nord Stream. Imports account for about $90 \%$ of total natural gas supply (Energy Information Administration, 2016).

\section{Conclusion}

In this paper, we have used the trans-log production approach to investigate the inter-fuel substitution elasticity between wind energy, nuclear energy and fossil fuels for the period 1986-2018 in the electricity sector of Germany. Due to the existence of multicollinearity among the regressors, the ridge regression approach has been used in the estimation process. The results reveal that wind and natural gas have positive output elasticity estimates, while the estimates for nuclear and coal are negative. We also found that all the inputs pairs have positive substitution elasticity estimates between them. With respect to wind energy, the highest substitutability estimate occurred with nuclear power which is followed by natural gas and then coal.

One of the policy implications of wind energy having positive output elasticity is that attempts of the authorities to increase wind energy will positively contribute to the economy through expansion in the country's gross domestic product. This also implies that negative shocks to wind energy consumption will negatively affect economic growth. Although natural gas also has a positive impact on economic growth, expansion of natural gas will lead to more emission in the economy due to its nature as a carbon emitting fossil fuel.

The implication of the results that provides evidence for substitutability among the inputs is that it is possible to substitute coal, natural gas and nuclear energy for wind energy in the electricity sector. On the one hand, wind energy can be used to substitute coal and natural gas, which cause emission. One the other hand, as the government in Germany continues to wind down the use of nuclear reactors, nuclear energy can be replaced with renewable energy sources, especially wind energy as against using substituting nuclear energy with fossil fuels. This possibility is underscored by the fact that only about $24 \%$ of the 60,822 megawatts of the installed wind turbine capacity was utilised in 2019 (British Petroleum, 2020). Therefore, the country has the capacity to increase wind energy for electricity generation. 
Hence, it is recommended that several policies should be introduced to encourage the usage of wind energy in the economy. One of such policies is the introduction of tax credit for wind energy technology. Such initiative is likely to decrease net project costs to consumers, encourage the adoption of wind energy technologies and boost market acceptance of clean energy projects. Another policy option that will yield the same result is the reduction in property taxes for wind power facilities. The effort to enhance grid connection guidelines, an effective financial system, the commitment on the part of the government to allocate fund for research and development (R\&D), in addition to synergy between the wind industry, science sector and the state are other initiatives necessary for the success of the wind industry. There is also a need for a mix of public policies that lead to an enabling atmosphere for the success of the wind industry.

The government in Germany has been initiating policies in this direction. For instance, the authorities in Germany have introduced remuneration scheme and the Feed-In-Tariff (FiT), which has led to greater longevity, transparency, and certainty for investors in the wind energy market. Besides, there has been an increase in the financing and deployment of wind energy technologies and erecting of wind turbines across the country (World Wind Energy Association, 2018). Therefore, the government should continue on the path of introducing policies aimed at encouraging wind energy development in the country.

\section{References}

Bello, M. O., Solarin, S. A., \& Yen, Y. Y. (2020). Interfuel substitution, hydroelectricity consumption and $\mathrm{CO} 2$ emissions mitigation in Malaysia: Evidence from a transcendental logarithm (trans-log) cost function framework. Environmental Science and Pollution Research, 27, 17162-17174.

British Petroleum (BP) (2020) Statistical Review of World Energy. Available at https://www.bp.com/en/ global/corporate/energy-economics/statistical-review-of-world-energy.html [25 July, 2020]

Energy Information Administration (2016). Country Brief, Germany. Available at https://www.eia.gov/inter national/analysis/world [25 July, 2020]

Hoerl, A. E. (1962). Applications of ridge analysis to regression problems. Chemical Engineering Progress, $58(3), 54-59$.

Hoerl, A. E., \& Kennard, R. W. (1970). Ridge regression: Biased estimation for nonorthogonal problems. Technometrics, 12(1), 55-67.

Hossain, A. N., \& Serletis, A. (2020). Biofuel substitution in the US transportation sector. The Journal of Economic Asymmetries, 22, e00161.

International Energy Association (2020). IEA World Energy Balances 2020. Available at https://www.iea. org/reports/world-energy-balances-overview [25 July, 2020]

Kim, K. (2019). Elasticity of substitution of renewable energy for nuclear power: Evidence from the Korean electricity industry. Nuclear Engineering and Technology, 51(6), 1689-1695.

Kuşkaya, S., \& Bilgili, F. (2020). The wind energy-greenhouse gas nexus: The wavelet-partial wavelet coherence model approach. Journal of Cleaner Production, 245, 118872.

Lin, B., \& Ankrah, I. (2019a). Renewable energy (electricity) development in Ghana: Observations, concerns, substitution possibilities, and implications for the economy. Journal of Cleaner Production, 233, 1396-1409.

Lin, B., \& Ankrah, I. (2019b). On Nigeria's renewable energy program: Examining the effectiveness, substitution potential, and the impact on national output. Energy, 167, 1181-1193.

Mugabe, D., Elbakidze, L., \& Zaynutdinova, G. (2020). Elasticity of substitution and technical efficiency: Evidence from the US electricity generation. Applied Economics, 52(16), 1789-1805.

Ortega-Izquierdo, M., \& del Río, P. (2020). An analysis of the socioeconomic and environmental benefits of wind energy deployment in Europe. Renewable Energy, 160, 1067-1080.

Solarin, S. A., \& Bello, M. O. (2019). Interfuel substitution, biomass consumption, economic growth, and sustainable development: Evidence from Brazil. Journal of Cleaner Production, 211, 1357-1366.

Tan, R., \& Lin, B. (2020). The influence of carbon tax on the ecological efficiency of China's energy intensive industries-A inter-fuel and inter-factor substitution perspective. Journal of Environmental Management, 261, 110252. 
The Conference Board. (2020). Economic data and analysis. Available at: https://www.conference-board. org/data/ [25 July, 2020]

The Guardian (2020). Offshore wind energy investment quadruples despite Covid-19 slump. Available at https://www.theguardian.com/environment/2020/jul/13/offshore-wind-energy-investment-quadruplesdespite-covid-19-slump [26 June, 2020]

World Bank Group (2020). World Development Indicators 2020. World Bank Publications.

World Wind Energy Association (2018). World wind energy association policy paper series. Available at: https://wwindea.org/wp-content/uploads/2018/06/Germany_Full.pdf [25 July 2020]

Publisher's Note Springer Nature remains neutral with regard to jurisdictional claims in published maps and institutional affiliations. 